\title{
Surrate
}

\section{PEMBERDAYAAN MASYARAKAT MELALUI KAMPUNG TEMATIK DI KELURAHAN PADANG NANGKA KECAMATAN SINGARAN PATI KOTA BENGKULU}

\author{
Romdana $^{1}$, Faridah $^{2}$, Marsidi $^{3}$, Ovita Charolina ${ }^{4}$ \\ Sekolah Tinggi Ilmu Administrasi (STIA) Bengkulu \\ Correponding author : romdanayahya123@gmail.com
}

\begin{abstract}
$\underline{\text { Abstrak }}$
Saat ini kemiskinan merupakan salah satu persoalan pemerintah dimana saja.seperti halnya Pemerintah kota Bengkulu. Berbagai macam kebijakan yang dilakukan guna untuk menekan angka kemiskinan salah satunya adalah dengan program pembangunan Kampung Tematik. Pengembangan masyarakat di dalam program Kampung Tematik di dasarkan pada asumsi nilai dan prinsip-prinsip agar dalam pelaksanaannya dapat memberdayakan masyarakat berdasarkan inisiatif. Kemampuan dan partisipasi masyarakat di dalam mewujudkan dan mensukseskan program kampung Tematik. Program Kampung tematik ini sekaligus Program pengabdian LPPM STIA Bengkulu yang bertujuan selain mengenalkan program pemerintah kepada masyarakat juga mendorong pelibatan partisipasi masyarakat suatu daerah tersebut. Tujuan Program kampung Tematik yang diluncurkan oleh pemerintah kota Bengkulu adalah salah satu program yang memadukan potensi/ciri khas setiap wilayah dengan masalah penganggulangan kemiskinan yang ada. Metode dalam pengabdian ini adalah Obsevasi, Sosialisasi dan pelaksanaan. Manfaat yang dirasakan setelah berdirinya usaha kampung tematik wirausaha ini perilaku sosialnya sedikit berubah masyarakatnya semakin peka terhadap kemajuan, berusaha untuk mengikuti setiap pelatihan yang di sampaikan. Kesimpulan dari hasil pengabdian ini Program Kampung tematik yang berjalan cukup baik namun perlu adanya program tematik ditempat lain supaya pemerataan sebagai langkah program pengentasan kemiskinan.
\end{abstract}

\section{Kata Kunci : Pemberdayaan, Kampung Tematik, Partisipasi}

\section{A. Pendahuluan}

Penanggulangan kemiskinan merupakan tugas dan suatu kewajiban pemerintah,baik itu Pemerintah Pusat maupun pemerintah daerah, sejak berlaku otonomi daerah , pemerintah daerah diberi keluasaan untuk mengatur dan megurus daerahnya sendiri.Pada intinya pembangunan itu bertujuan untuk meningkatkan kesejahteraan masyarakat. Pemerintah kota Bengkulu meluncurkan Program Kampung Tematik untuk meningkatkan kesejahteraan masyarakat melalui peningkatan potensi dan identitas lokal..

Identitas lokal tersebut
merupakan cerminan terhadap
potensi sumber daya alam dan
manusia yang ada di setiap kampung


Tematik. Program kampung Tematik

Kota Bengkulu di mulai sejak tahun 2018 yang diinisiasi melalui pemodelan Kampung Tematik, kerjasama antara Pemerintah kota Bengkulu dan Perguruan Tinggi yang ada di kota Bengkulu. Salah satu kerja sama dengan Perguruan tinggi yaitu Sekolah Tinggi Ilmu Administrasi (STIA) Bengkulu.yang lokasinya beralamat di Kelurahan Padang Nangka.kecamatan Singaranpati Kota Bengkulu yang diberi nama 'Kampung wirausaha

Program Kampung Tematik diluncurkan oleh pemerintah kota Bengkulu memberikan dampak positif bagi keberhasilan pembangunan kota Bengkulu.Hal ini dapat dilihat persentase penduduk miskin di kota Bengkulu yang mengalami penurunan yaitu pada September tahun 2018 sebesar 14,94 $\%$ dan turun pada september 2019 menjadi $14,13 \%$.

Program kampung Tematik yang diluncurkan oleh pemerintah kota Bengkulu adalah salah satu program yang memadukan potensi/ciri khas setiap wilayah dengan masalah penganggulangan kemiskinan yang ada. Pengembangan Masyarakat di dalam program kampung tematik didasarkan pada asumsi, nilai dan prinsip-prinsip agar dalam pelaksanaannya dapat memberdayakan masyarakat berdasarkan inisiatif, kemampuan dan partisipasi Pegawai Negeri (KPN) Pemda Provinsi Bengkulu memiliki jumlah aktiva lancar yang besar dan memiliki hutang lancar yang kecil, sehingga

berpengaruh buruk pada profitabilitas perusahaan yaitu kemungkinan tidak tertagihnya piutang sangat besar. Masyarakat sendiri di dalam mewujudkan dan mensukseskan Program kampungTematik yang ada di wilayah , karena partisipasi masyarakat sangat penting dalam pengembangan masyarakat dan keberhasilan program kampung tematik sebagai program penanggulangan kemiskinan .

Kampung Wirausaha adalah salah satu nama kampung tematik kota Bengkulu yang telah sukses dilounching oleh bapak wakil walikota Bengkulu yang berdiri Outlet kampung Wirausaha beralamat di kelurahan padang Nangka. Pembangunan kampung Tematik ini sudah diserahkan oleh STIA Bengkulu kepada pihak UPK (Unit Pelaksana Kegiatan) yang melibatkan 
orang-orang yang berada di

lingkungan

RT.tersebut.Untuk

pendamping hanya sebatas mengawasi dari pembangunan

tersebut.

\section{B. Metode}

Program Pemberdayaan melalui Pengabdian masyarakat melalui kampung Tematik ini dilaksanakan dengan 3 metode pelaksanaan: Pertama: Observasi, Kedua : Sosialisasi dan Ke-Tiga :Pelaksanaan, yang Rincian Sebagai Berikut:

\begin{tabular}{|c|c|c|}
\hline No & $\begin{array}{c}\text { Metode } \\
\text { Pengabdian }\end{array}$ & Kegiatan \\
\hline 1 & Observasi & $\begin{array}{lr}\text { Observasi } & \text { lapangan } \\
\text { untuk } & \text { melihat } \\
\text { kondisi } & \text { lapangan } \\
\text { bersama } & \text { tim } \\
\text { Bapelitbang } & \\
\text { Kelurahan } & \text { LPPM } \\
\text { STIA } & \text { untuk } \\
\text { memastikan } & \\
\text { lokasi,karakter } \\
\text { masyarakat } \\
\text { kondisi sosial }\end{array}$ \\
\hline 2 & Sosialisasi & $\begin{array}{l}\text { Memberikan } \\
\text { sosialisasi sekaligus } \\
\text { pendampingan dan } \\
\text { mengedukasikan } \\
\text { ketengah } \\
\text { masyarakat } \\
\text { mengenai kampung } \\
\text { Tematik ran } \\
\text { manfaatnya setelah } \\
\text { dibangun }\end{array}$ \\
\hline 3 & Pelaksanaan & $\begin{array}{l}\text { Melaksanakan } \\
\text { Pendampingan } \\
\text { Pembangunan } \\
\text { Kampung Tematik } \\
\text { sampai r pada }\end{array}$ \\
\hline
\end{tabular}

peresmian

\section{Hasil Pengabdian Masyarakat}

Pelaksanaan program kampung tematik dimulai sejak tahun 2018 yang diberi nama ' kampung Wirausaha " yang beralamat di Kelurahan Padang Nangka RT.15 Kecamatan SingaranPati kota Bengkulu. Awal dari program kampung Tematik ini sendiri sebenarnya bagian program Pemerintah Kota Bengkulu yang intinya bagaimana Perguruan Tinggi ambil bagian untuk memberikan sumbangsih pemikiran terhadap pembangunan di kota Bengkulu, sehingga Perguruan Tinggi diberi kewenangan sebagai Fasilitator untuk pembangunan kampung Tematik itu sendiri.

Melalui Kampung Tematik ini harapan pemerintah kota Bengkulu program penanggulangan kemiskinan sedikit bisa teratasi. Setidaknya kehadiran kampung tematik di wilayah kelurahan padang nangka tepatnya lokasi di RT.15 ini yang diberi nama Kampung Wirausaha. Kampung ini merubah mindset masyarakat sekitar.lokasi kampung wirausaha khususnya dan kelurahan Padang Nangka umumnya. Bagaimana bentuk bantuan pemerintah dalam bentuk pembangunan outlet tempat wirausaha ini bisa memotivasi masyarakat sehingga berusaha untuk berdikari 
 \\ Ournate}

menggeluti usaha yang selama ini sudah ada.
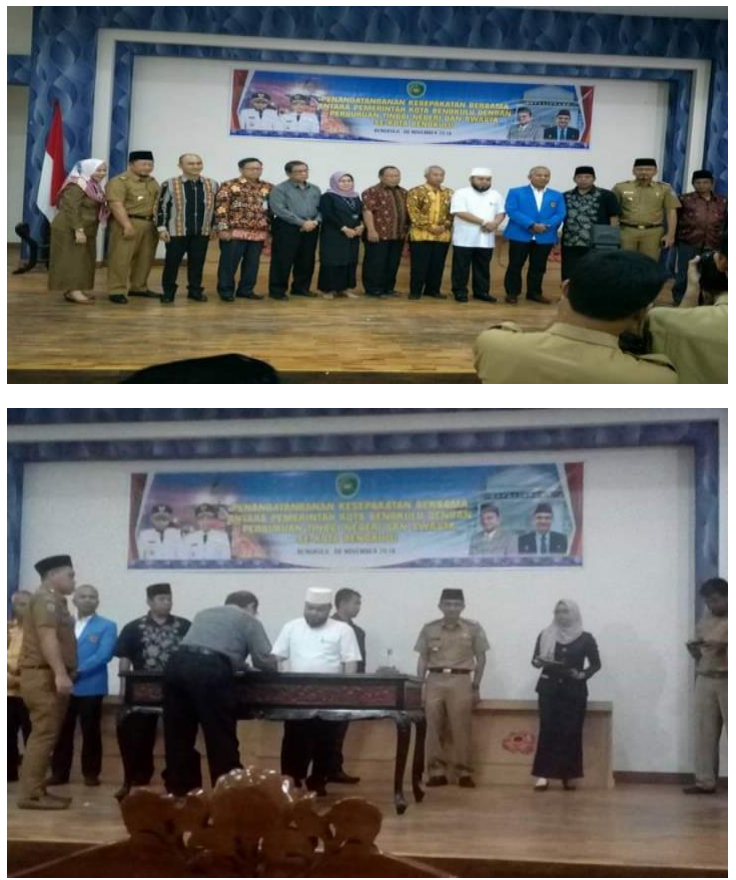

Gambar

1.

Dokumentasi penandatanganan Kerjasama ( MOU ) Perguruan Tinggi dengan Pemerintah Kota Kota Bengkulu

Setelah proses kerja sama ini dilakukan berarti tanggung jawab proses pembangunan dan bagaimana proses pendekatan dan sosialisasi di tengah masyarakat di serahkan ke Perguruan Tinggi dalam hal ini Sekolah Tinggi Ilmu Administrasi ( STIA ) Bengkulu

\section{Pemberdayaan dan keterlibatan masyarakat}

Masyarakat di sekitar Kelurahan padang Nangka bermata pencaharian Pedagang, buruh dan sebagian ada yang pegawai baik itu negeri maupun swasta dan Kelurahan Padang Nangka kebetulan berdekatan juga dengan Pasar panorama.

Hasil survey kami LPPM STIA bersama TIM monitoring dari Bapelitbang Kota beserta aparatur pihak Kecamatan Singaranpati dan Kelurahan maka Kelurahan Padang Nangka layak untuk mendapat hadiah pembangunan kampung tematik. Potensi yang bisa dikembang di kelurahan Padang Nangka ini banyaknya pengrajin industry rumah ( Home indistri ) yang merupakan kelompok kecil masyarakat atau komunitas beberapa masyarakat yang membuat makanan kecil atau mainan pernak pernik hiasan yang selama ini masyarakat itu sendiri bingung untuk memasarkan hasil kerajinan mereka tersebut.
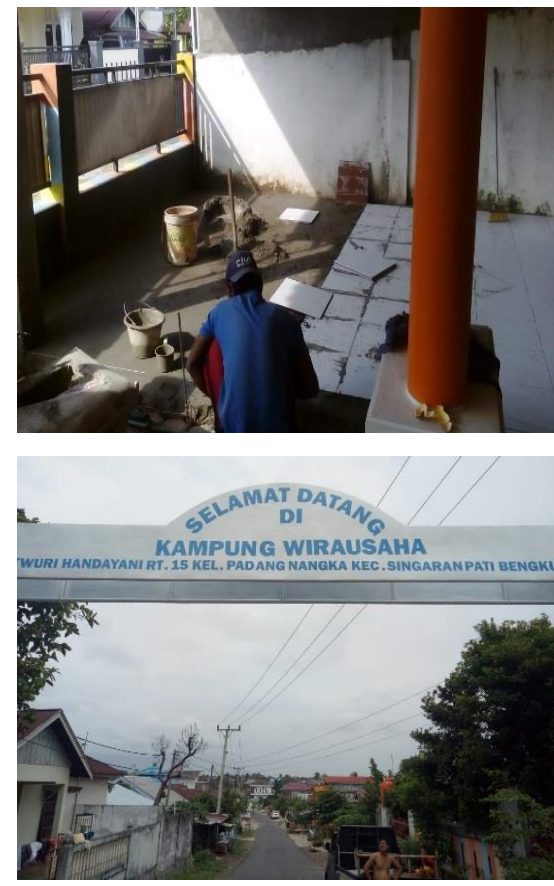

Gambar

Pembangunan Wirausaha

Untuk menjawab harapan dan impian kelompok pengrajin masyarakat 
 \\ Ournate}

tersebut solusi yang di tawarkan pemerintah Kota Bengkulu melalui kerjasama dengan Perguruan Tinggi yaitu pihak LPPM Sekolah Tinggi Ilmu Administrasi (STIA) Bengkulu maka dibangunlah Outlet Kampung Wirausaha. Yang selama ini usaha dagangan seperti: Pembuatan tas rajutan, kue kering dan jenis makanan ringan lainnya, Outlet kampung Tematik ini bisa digunakan untuk menitip berbagai karya ibu-ibu dan kelompok usaha lainnya sehingga bisa tertata rapi di dalam etalase yang ada di outlet kampung wirausaha itu. Begitupun usaha kue-kue kering milik ibu Sundari dan bapak David ini yang selama ini pemasaran kue-kue keringya hanya kerumah-rumah dan kantor setelah ada outlet kampung Wirausaha ini pemasarannya pun mudah di pasarkan dan masyarakat lebih yakin keberadaan kampung wirausaha ini karena didukung oleh pemerintah kota dan Perguruan Tinggi sebagai pendamping.

Selain itu juga kelompok sosial seperti arisan ibu-ibu RT juga tertarik untuk membuat kerajinan tangan seperti pembuatan boneka wisudah yang selama ini tidak pernah terpublikasi akhirnya muncul dengan adanya outlet kampung Wirausaha ini.ini adalah contoh bahwa keberadaan Kampung Wirausaha ini memberikan dampak yang luar biasa untuk merubah perilaku masyarakat tadinya hanya pasif sehingga secara berangsur mulai tumbuh dan berkembang jiwa kewirausahaannya.

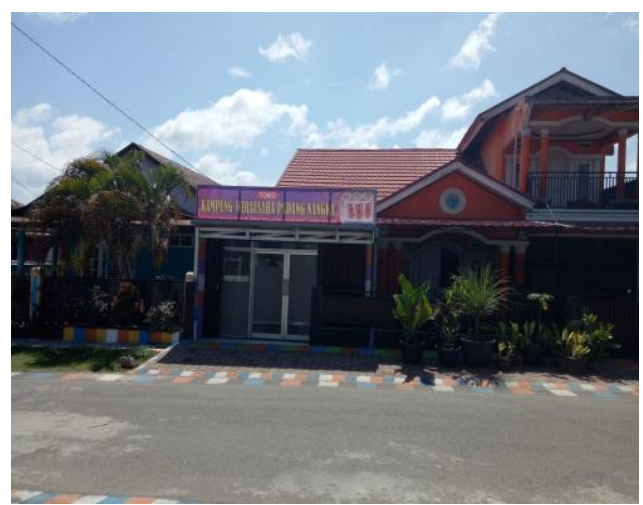

Gambar 3. Dokumentasi Outlet Kampung Wirausaha LPPM STIA Bengkulu 2019

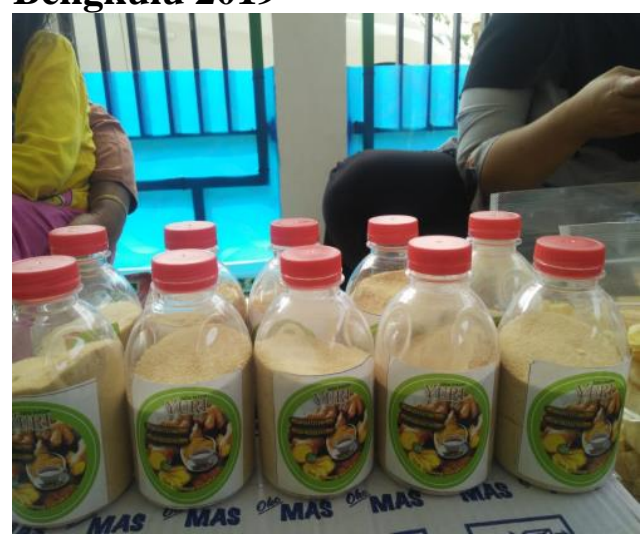

Gambar 4. Dokumentasi hasil karya ibu-ibu dan masyarakat

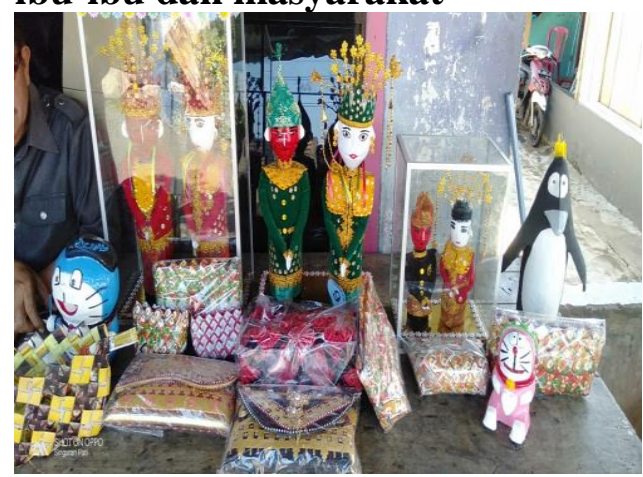

Gambar 5. Hasil kerajianan Ibu-ibu warga Kelurahan Padang Nangka

Proses pembuatan aneka barang boneka pasangan pengantin adat Bengkulu ini sangat menarik untuk di lihat karena 
semua bahannya berasal dari barang bekas sehingga ibu-ibu yang ingin mendapatkan bahannya tidak terlalu sulit.Inilah salah satu hasil usaha ibu-ibu warga yang ikut kelompok wirausaha yang tergabung dalam kampung Wirausaha.Disamping kegigihan ibu-ibu dan kelompok usaha mandiri ini untuk mengembangkan usaha mereka lokasi Outlet yang sekarang jadi tempat lokasi kampung Wirausaha adalah milik Pribadi bapak David dan ibu Sundari mereka ini i usaha yang sudah ada kumunitas ibu-ibu yang diketuai ibu RT ini juga aktif ikut pelatihan kewirausahaan di dinas UMKM yang di bimbing pendamping dari LPPM STIA Bengkulu, mereka semangat sekali setiap mengikuti workshop kewirausahaan hal ini menandakan keingintahuan mereka untuk maju setidaknya merubah cara berfikir mereka untuk selalu berinovasi mengembangkan usaha yang sudah ada dan mempelajari bagaimana manajemen yang baik terhadap suatu usaha sehingga bisa berkembang dengan baik.

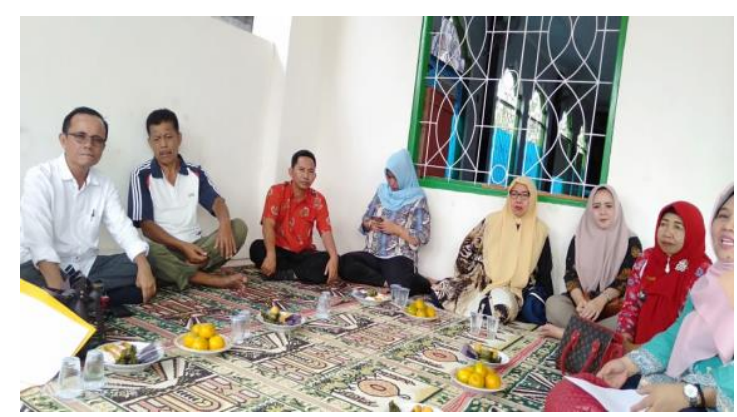

Gambar 6. Dokumen , monitoring dari LPPM STIA
Kita LPPM STIA Bengkulu beserta tim monitoring dari awal proses pembangunan Kampung Tematik sampai kepada peresmian selalu melakukan monitoring.tahap demi tahap hasil monitoring kita sealu mengalami perubahan walaupun tidak begitu kelihatan satu hal yang sangat perhatikan keberadaan kampung Tematik ini memberikan dampak perubahan yg lumayan karena kalau dibandingkan dengan sebelum adanya kampung Tematik perubahan perilaku cara berfikir mereka masih bersifat stagnan atau menunggu dengan adanya kampung wirausaha ini keingin tahuan mereka cukup besar indikasinya setiap ada pelatihan mereka selalu ikuti.

\section{Kesimpulan}

Berdasarkan hasil pengabdian masyarakat berupa program pembangunan kampung tematik yang berbasis pemberdayaan masyarakat, dapat disimpilkan :

a. Masyarakat sangat antusias mengikuti setiap tahapan program kampung tematik, pembangunan aoutlet dan kebersihan lingkungan untuk keindahan dan kerapian kampung dan outlet wirausaha tersebut. 
b. $100 \%$ kelompok wirausaha

DAFTAR PUSTAKA

kelurahan padang nangka dapat mengikuti kegiatan sosialisasi dan workshop yang di adakan Dosen STIA Bengkulu dan Bapelitbang kota bengkulu dari awal hingga selesai kegaiatan

c. Pembangunan Kampung tematik berupa outlet dan taman mencapai $100 \%$ sesuai dengan dana stimulus yang diberikan pemerintah kota Bengkulu

d. Modal sosial yang tinggi ditengah masyarakat membuat masyarakat kesadaran individunya tinggi sehingga mereka terpacu untuk maju. Disisi lain selain program ini berjalan dengan baik namun saran yang perlu disampaikan demi mewujudkan proram yang lebih baik dan berkembang anatara lain Program kampug Tematik yang berorientasi pemberdayaan ini hendaknya tiap tahun dilakukan dengan cara perpindahan lokasinya sehingga bisa ikut memeratakan program Pemberdayaan ini.
Zubaedi, (2013), Pengembangan Masyarakat (Wacana \& Praktik, Prenada Media Group, Jakarta.

Edi, Suharto.2005.Membangun

Masyarakat Memberdayakan Rakyat Kajian

Strategis

Pembangunan

Kesejahteraan Sosial dan Pekerjaan

Sosial. Bandung : PT. Refika Aditama.

Kinanti,Anissa 2019 "Pemberdayaan Mayarakat dalam Kampung Tematik" https://ejournal3.undip.ac.id/index.php/jpg s/article/viewFile/23553/21451

diakses 3 agustus 2020, pukul 09.45

https://bengkuluekspress.com/ 15,Januari 2020

https://bengkuluekspress.com/angka-

kemiskinan-di-bengkulu-turun-signifikan/ diakses ,4 Agustus 2020 ,pukul 11.59

Maisaroh, S.\& Sukhemi. (2011).

Pemberdayaan Masyarakat Melalui

Pengembangan

Budaya Kewirausahaan untuk

Mengurangi Pengangguran dan

Kemiskinan.

Jejak, 4 (1). 23-33. 